\title{
Afterword
}

\section{Page and Stage, Pasts and Futures}

\section{Stuart Sillars}

In 1733, a small volume appeared bearing on its title page the impressive words "Bell's Edition of Shakespeare's Plays" (Figure 1). The writing went on to assure the reader that the scripts were "regulated from the prompt books" of the two patent theatres, still the only stages on which the plays could legally be performed. In 1788, Bell published the plays again (Figure 2), in volumes that, resting on textual study, contained the exoskeleton of annotations and explanations that, since Pope, Theobald and most significantly Johnson, had become essential. The difference between the two is well summarised in a paragraph from the opening of the earlier:

Though this is not an edition meant for the profoundly learned, nor the deeply studious, who love to find out, and chace their own critical game; yet we flatter ourselves both parties may perceive fresh ideas started for speculation and reflection.

From this it is easy to see that the anti-theatrical prejudice of sometime moralists has been displaced by a more contemporary, and perhaps still current, anti-intellectual one, the inference that chasing their own critical tails is of more interest to the learned and studious (read the silent so-called before each noun) clearly audible to those familiar with English irony. It is perhaps continued in the names by which each came to be known: the "Acting" and the "Literary". Revealing in itself of the treatment of Shakespeare at the end of the century, the distinction between these two editions, not generally regarded as important within the succession of editors - Rowe, Pope, Theobald, Johnson, and the subsequent efforts of the Eminent Victorians - establishes a point of contention that remains at the heart of the editing process: do the plays attempt to record or reveal a performance, or seek to establish and illumine the holy grail of an ideal literary construct?

Such a dilemma remains for all editions, and all editors. In this category should be included also all readers, since even a decision not to consider the movement of actors on stage, and most particularly those of performers not speaking, is a statement about what a Shakespeare play is. The distinction established by Bell's editions has its direct descendant in those of Cambridge University Press, whose Shakespeare in Production series presents the plays with annotations recording moments of setting, emphasis or stage business from the earliest recorded staging to the most recent. But the schism is not absolute. In the last two decades the individual plays of the New Cambridge Shakespeare began to appear as "revised versions," with introductions extended to include sections discussing major treatments on stage and in film. 


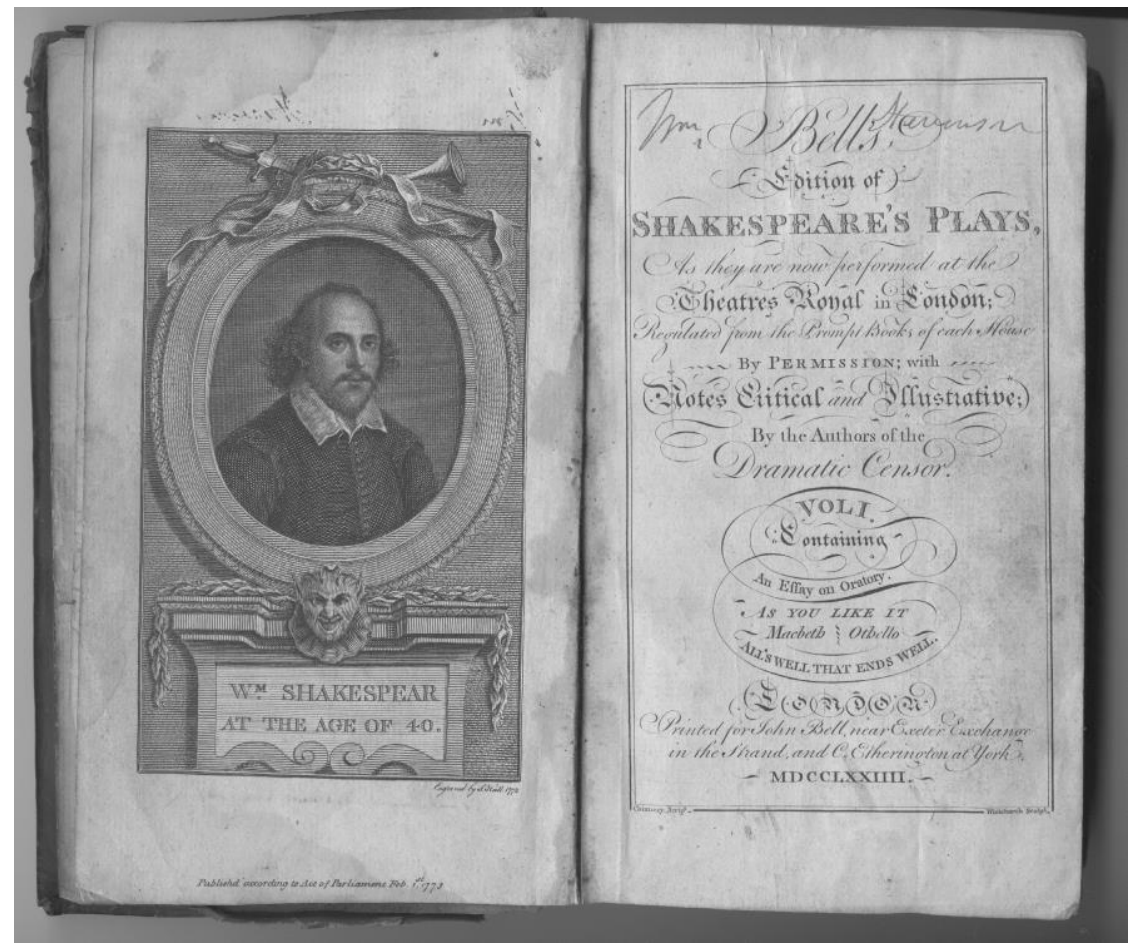

Figure 1 Bell's Edition of Shakespeare's Plays (1733)

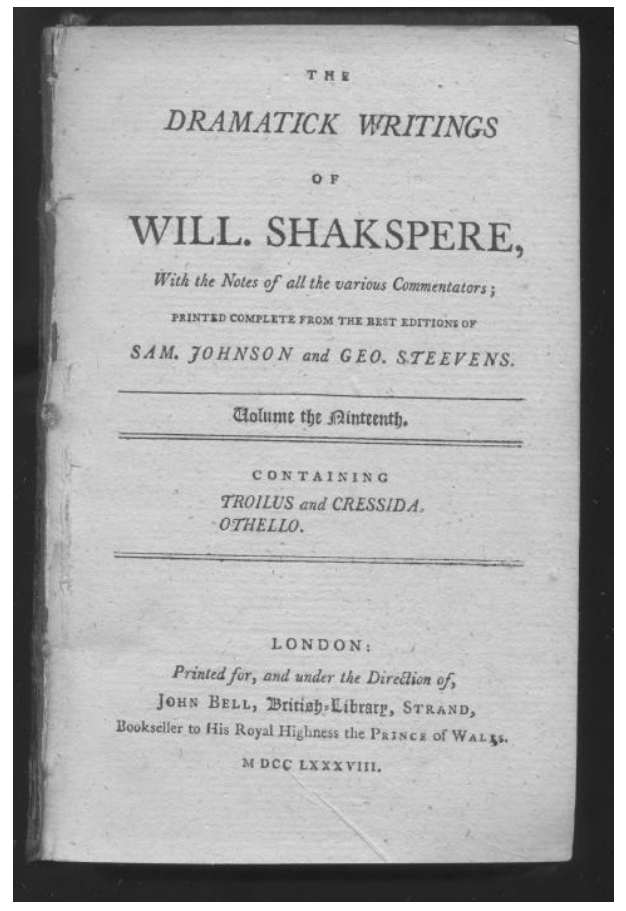

Figure 2 Bell's 1788 edition
That the two need not, and indeed should not, be kept wholly separate - a duel as pointless and unfulfilled, perhaps, as that between Viola and Aguecheek - is implicit in some criticism. Helen Cooper's analysis of what is essentially an unscripted moment in A Midsummer Night's Dream is important in exploring an aspect of that play, but also in addressing the larger question of the authenticity and value of act and scene divisions in the plays. It is also seen repeatedly in stage directions and annotations in countless editions that seek to clarify the reader's experience. The results can be teasingly assertive. We know that in many early published versions the habit was to give the names of all those taking part in a particular scene at its very beginning, not those who are on stage from the 
very outset; and the addition of apparently simple instructions such as "Enter" or "Exit" is manipulative in terms of character, action and idea. When precisely does Hamlet enter to hear Claudius at prayer? How present is Othello in overhearing and soliloquising as his plot, and that of the play, develops? Here, the editor performs the function of an actor, actormanager, producer or director, to give the names chronologically applied to those who decide such things in the theatre.

Silences are also revealing. For the Victorians, and for later generations brought up on Tillyard and the Great Chain of Being, Thersites' speech beginning "Take but degree away" had about it a near-Mosaic authority in stating the hierarchy of renaissance society. Add to it a consideration of how the other figures on stage react, or fail to react, to it during its considerable length, and something rather different may well emerge. Much the same might be said of Jessica's response to Lorenzo's explanation of the harmony of the spheres - pace Vaughan Williams - at the close of The Merchant of Venice. It's a speech of great beauty and richness, but even at the time of its writing it would surely have been seen as, let us say, on the verge of being outmoded. And certainly the implications of social order are overturned, both by the sense and the bawdy overtones, of the ring conceit that follows. So how would Jessica respond on stage?

These are, of course, not all within the responsibility of the editor; but they depend on the preparation of a printed text that shows awareness of stage movements, and might benefit from allusions to stage practice. To include such allusions as notes in the text would make them integral with the reading; to keep them in an introductory section would again erect the barrier between study and stage; and the final decision, or more effectively the final complex of unresolved possibilities, lies with the reader, who becomes the final producer in the editorial-performative process.

All this, of course, depends on the idea of a text that itself makes choices of many kinds. The battle between original and revised spelling was, for most on both sides of the editing table, resolved at the end of the nineteenth century; larger contests between Folio and Quartos remain unresolved, in most cases quite positively so. In terms of detail, many earlier editions operated through a process of multiple triangulation, internal and external inference, and in some cases inspired, lyrical guesswork, to establish a putative authorial final version. Such choices, resting on principles such as the difficilior lectio, in which the harder and less likely of two possibilities was taken to be the more satisfactory, appeared along with careful justifications in footnotes or longer appendices. But the last half-century has seen a move away from these choices, the consequences of which extend much further than the identity of individual textual moments.

The key example here is the three successive editions of Hamlet in the Arden Shakespeare. The first, appearing as the initial play in the series, was produced by Edward Dowden in 1899 and constructed its text from various elements of the Quartos and Folio along the lines sketched out above. Its introduction extends to 19 pages, and its commentary notes are extended by four pages of "Addenda," short 
clarifications from "a mass of invaluable illustrations and additions" added at proof stage "by Mr W.J. Craig." An appendix of the same extent contains "Some Passages from the Quarto of 1603," and two pages discuss the players' "travelling" at 2.2.347.

Only in 1982 was this edition replaced, with the version by Harold Jenkins. It resolved many issues of detailed textual choice and gave succinct summaries balancing Quartos against Folio, added a collection of Longer Notes extending to a little over 150 pages, and patiently explained some of the processes involved in a section from the Introduction titled "The editorial problem and the present text". The volume was for many years considered one of the finest and most reliable editions, deftly solving issues general and specific and at the same time revealing the very nature of such problems and the work their resolution demanded, while in many cases leaving the specialist or persistent reader free to disagree. A different approach is taken by the most recent and still current Arden edition by Ann Thompson and Neil Taylor. This gives the complete text of the Second Quarto, with an Appendix giving passages found only in the Folio. Alongside this, a second volume contained the texts of the First Quarto (1603) and the Folio. Together, the two made available all of the main textual variants, along with the problems and delights that accompany them, while still allowing, through the first volume, a reading more closely resembling the play that was for generations referred to as Hamlet. The venture was hailed as both an ideal single text and a full exploration of variants for the specialist reader.
At roughly the same time, a collaborative endeavour known as The Quartos Project was launched. It brought together different copies of all the Quartos in the collections of the Folger Shakespeare Library, the British Library and other major international collections, and issued them all as an online database. Fully interactive, it allowed readers to compare individual volumes and thus construct surveys of textual detail, the historical movements of passages before the Folio, and in general explore all the features in any and all of the Quarto forms of the play. Together with the new Arden, this made clear in practical terms something apparent for some years: the internet would change the whole process of textual editing and presentation. Other, similar ventures followed.

The precise nature of these changes is worth exploring. The principal readers - these days one is tempted to say customers - for the singleplay editions, Arden, Oxford, New Cambridge and, to a lesser degree, Penguin - had for many decades towards the end of the twentieth century been students, either at undergraduate or pre-university level. For them, the emphasis was on exploration of idea, technique and perhaps character: textual variants were addressed only where issues of clarification were involved. The multiplicity of text now available in print and online introduced not simply more detailed textual study but a largely new discipline of comparative textual exploration and construction - certainly new to the great majority of its adherents. The page was now multiple and fluid, the focus on exploring its growth and comparing its forms; the growing interest in book history enriched this by adding 
concerns with material culture, paratextuality, illustration, and patterns of circulation. Yet balancing and offsetting this were two other forces. One was the theoretical explosion that hit English universities, rather later than those in Europe, and moved the study of Shakespeare into different areas, the single overriding idea being of greater significance than concepts of textual purity. The other was the far greater imaginative freedom in production, which delved ever further into remote areas of setting, costume, textual cutting and reassembly, and in general a concern for what the moment presented in balance, and often seemingly in conflict, with what to many appeared the main thrusts of the play text.

Given all these forces, it would seem that the division between page and stage, each now splintered into separate ideologies and practices, is only one of the complex antitheses and seeming conflicts that anyone addressing Shakespeare, for whatever purpose and in whatever physical or ethereal identity, must confront. And this is to say nothing of Manga Shakespeare, comic-book Shakespeare, Shakespeare on film, or what might be termed a larger resepsjonsestetikk: studies of Shakespeare in painting, opera, musicals, and other aesthetic transmediations. Whether this is a con- summation devoutly to be wished, or simply a consummation, is for the individual to decide. But the alternatives are not always welcome. Those editions that offer a complete account of a play - earlier the Signet, more recently the Norton - by including a series of critical essays that purport, if not openly then often in practice, to say everything that a reader needs to know about a play, have something in common with sharply focused theoretical applications: both seem closely to approach Newton's vision and a single sleep.

The essays in this number would seem to suggest that the idea of editing, with all its difficulties and insoluble questions - and, with luck, controversies - is alive and well, way beyond anything dreamed of by John Bell, who seemed to have all the options covered in his two editions in the 1770 s.

At Cambridge in October 1928, Miss Beryl Paston Brown bought a copy of Dowden's Hamlet and made copious pencilled annotations within the text (Figure 3). They refer both to issues of textual transmission and possible performance practices: they suggest that, then as now, not only can we all attempt to be readers in both performative and textual fields, but now every reader is also a practical editor. 


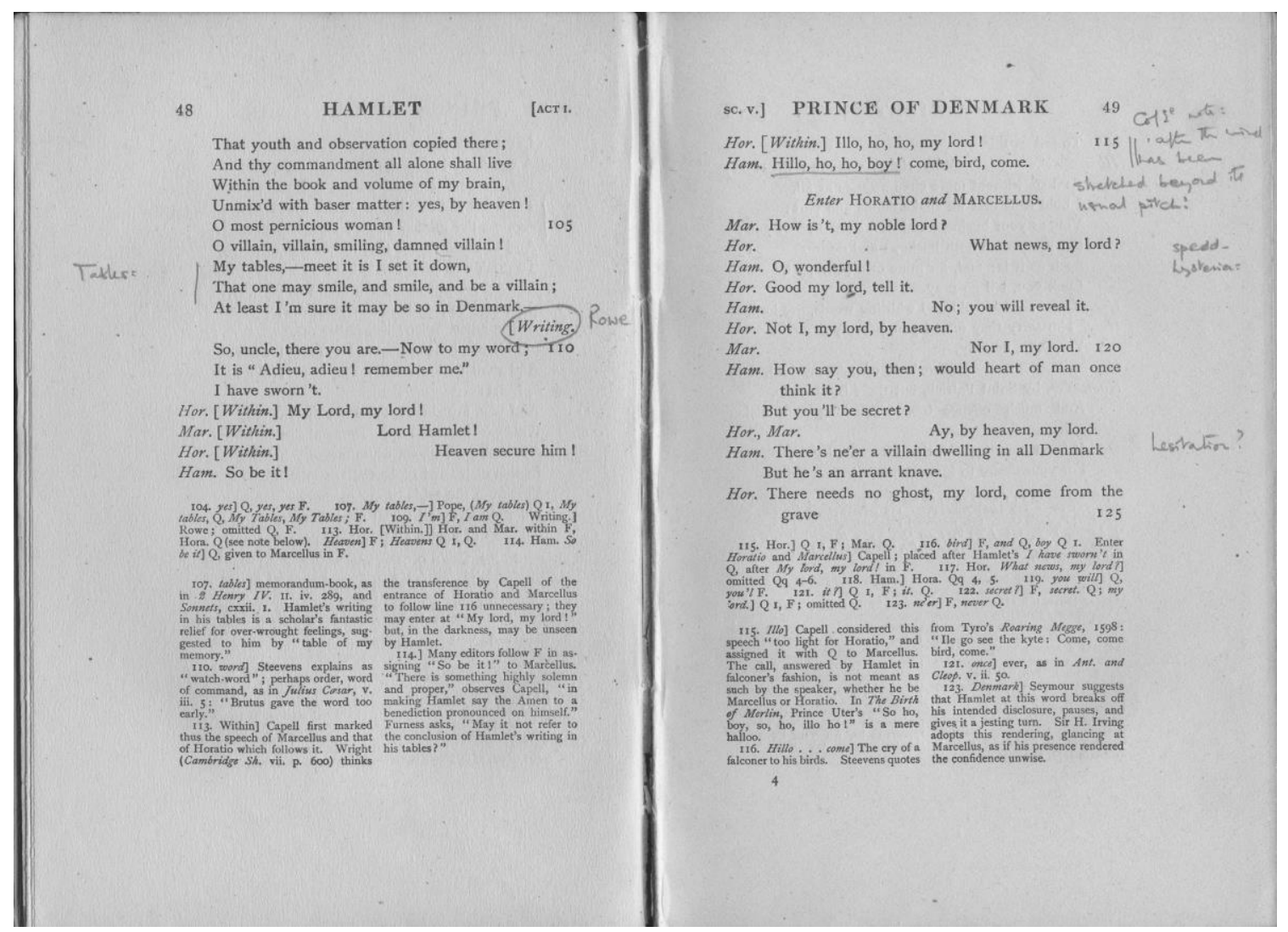

Figure 3 Beryl Paston Brown's annotated edition of Dowden's Hamlet 